\title{
Retraction Note to: Prolonged food restriction decreases body condition and reduces repeatability in personality traits in web-building spiders
}

\author{
James L. L. Lichtenstein ${ }^{1}$. Nicholas DiRienzo ${ }^{2} \cdot$ Karen Knutson $^{1} \cdot$ Candice Kuo ${ }^{1} \cdot$ Katherine C. Zhao $^{1}$. \\ Hayley A. Brittingham ${ }^{1} \cdot$ Sara E. Geary ${ }^{1} \cdot$ Sam Ministero ${ }^{1} \cdot$ Henry K. Rice ${ }^{1} \cdot$ Zachary David $^{1} \cdot$ Inon Scharf ${ }^{3}$. \\ Jonathan N. Pruitt ${ }^{1,4}$ \\ Published online: 10 March 2021 \\ (C) Springer-Verlag GmbH Germany, part of Springer Nature 2021
}

Retraction Note to: Behav Ecol Sociobiol (2016) 70:1793-1803

https://doi.org/10.1007/s00265-016-2184-1

This article (Lichtenstein et al. 2016) has been retracted by the Editors-in-Chief at the request of authors James Lichtenstein, Nicholas DiRenzo and Zachary David. After publication the authors found anomalies in the raw data that were collected. The conclusions presented based on these data are therefore unreliable. Katherine Zhao, Sara Geary, Sam Ministero and Inon Scharf agree with this retraction. Jonathan Pruitt does not agree with this retraction. Karen Knutson, Candice Kuo, Hayley Brittingham and Henry Rice have not responded to correspondence from the Editors-in-Chief or the Publisher about this retraction.

\section{Reference}

Lichtenstein JLL, DiRienzo N, Knutson K, Kuo C, Zhao KC, Brittingham HA, Geary SE, Ministero S, Rice HK, David Z, Scharf I, Pruitt JN (2016) Prolonged food restriction decreases body condition and reduces repeatability in personality traits in webbuilding spiders. Behav Ecol Sociobiol 70:1793-1803. https://doi. org/10.1007/s00265-016-2184-1

Publisher's note Springer Nature remains neutral with regard to jurisdictional claims in published maps and institutional affiliations.

The online version of the original article can be found at https://doi.org/ $10.1007 / \mathrm{s} 00265-016-2184-1$

James L. L. Lichtenstein

j11134@pitt.edu

1 Department of Biological Sciences, University of Pittsburgh, Pittsburgh, PA 15260, USA

2 Department of Ecology and Evolutionary Biology, University of Arizona, Tucson, AZ 85721, USA

3 Department of Zoology, Tel Aviv University, Tel Aviv, Israel

4 Department of Ecology, Evolution, and Marine Biology, University of California Santa Barbara, Santa Barbara, CA 93106, USA 